\title{
Involvement of fibroblast growth factor 2 (FGF2) and its receptors in the regulation of mouse sperm physiology
}

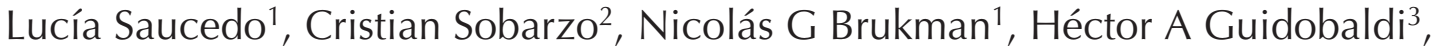 \\ Livia Lustig², Laura C Giojalas³ ${ }^{3}$ Mariano G Buffone1, Mónica H Vazquez-Levin¹,* \\ and Clara Marín-Briggiler ${ }^{1, *}$
}

${ }^{1}$ Instituto de Biología y Medicina Experimental (IBYME), Buenos Aires, Argentina, ${ }^{2}$ Instituto de Investigaciones Biomédicas, CONICET-UBA, Buenos Aires, Argentina and ${ }^{3}$ Instituto de Investigaciones Biológicas y Tecnológicas (UNC, CONICET, FCEFyN) and Centro de Biología Celular y Molecular, UNC, FCEFyN, Córdoba, Argentina

Correspondence should be addressed to C Marín-Briggiler; Email: cmarin@ibyme.conicet.gov.ar

*(M H Vazquez-Levin and C Marín-Briggiler contributed equally to this work)

\begin{abstract}
Fibroblast growth factor 2 (FGF2) and its receptors (FGFRs) have been described in several tissues, where they regulate cellular proliferation, differentiation, motility and apoptosis. Although FGF2/FGFRs expression in the male reproductive tract has been reported, there is scarce evidence on their presence in the female reproductive tract and their involvement in the modulation of sperm function. Therefore, the objective of this study was to determine the expression of FGF2 in the female reproductive tract and to assess the role of the FGF2/FGFRs system in the regulation of sperm physiology using the murine model. FGF2 was detected in uterus and oviduct protein extracts, and it was immunolocalized in epithelial cells of the uterus, isthmus and ampulla, as well as in the cumulus oophorus-oocyte complex. The receptors FGFR1, FGFR2, FGFR3 and FGFR4 were immunodetected in the flagellum and acrosomal region of sperm recovered from the cauda epididymis. Analysis of testis sections showed the expression of FGFRs in germ cells at different stages of the spermatogenesis, suggesting the testicular origin of the sperm FGFRs. Sperm incubation with recombinant FGF2 (rFGF2) led to increased sperm motility and velocity and to enhanced intracellular $\mathrm{Ca}^{2+}$ levels and acrosomal loss compared to the control. In conclusion, this study shows that FGF2 is expressed in tissues of the female reproductive tract. Also, the fact that functional FGFRs are present in mouse sperm and that rFGF2 affects sperm motility and acrosomal exocytosis, suggests the involvement of this system in the in vivo regulation of sperm function.
\end{abstract}

Reproduction (2018) 156 163-172

\section{Introduction}

Fibroblast growth factors (FGFs) comprise a family of more than 20 proteins, divided into seven subfamilies. Among them, FGF2 is the best-characterized member (Ornitz \& Itoh 2001, Yu et al. 2007). The biological activities of FGFs are mediated by their binding to specific receptors (FGFRs), composed of three extracellular immunoglobulin-like domains, a single transmembrane domain, and two cytoplasmic domains containing the catalytic tyrosine kinase core (Givol \& Yayon 1992, Johnson \& Williams 1993). The most studied FGFRs are known as FGFR1, FGFR2, FGFR3 and FGFR4. Transcripts coding the third extracellular domain of FGFR1, FGFR2 and FGFR3 are subjected to alternative splicing, giving rise to two receptor isoforms (IIIb and IIIC), with different ligand-binding properties and specific tissue expression (Gong 2014). Evidence in somatic cells indicates that interaction of FGFs with heparin or heparan sulfate proteoglycans (HSPGs) allows their binding to the FGFRs, triggering receptor dimerization and autophosphorylation (Mohammadi et al. 2005). FGFR signal transduction results in the activation of several pathways (including STAT, MAPK and PI3K pathways), leading to the phosphorylation of transcription factors and the expression of FGF-target genes (Eswarakumar et al. 2005).

Members of the FGFs and FGFRs families have been identified in a variety of tissues (Hughes 1997, Fon Tacer et al. 2010), and the FGFs/FGFRs signaling has been implicated in many cellular processes, such as cell proliferation, differentiation, adhesion, survival, apoptosis, motility and chemotaxis. It has been reported that this system is involved in the development and maintenance of normal tissues, but also in tumor progression (Turner \& Grose 2010, Belov \& Mohammadi 2013, Ornitz \& Itoh 2015). Despite the high amount of evidence on the role of FGFs and FGFRs in different tissues, including the reproductive ones, there is not enough 
information of their relevance in the regulation of gamete physiology.

Mammalian sperm are produced in the testis by spermatogenesis and undergo a maturation process during their transport through the epididymis. Ejaculated sperm are not able to fertilize an egg; to become fertilization competent, sperm must undergo a series of biochemical modifications in the female reproductive tract, collectively known as capacitation. Capacitation is associated with an increase in sperm intracellular $\mathrm{Ca}^{2+}$ levels and in protein tyrosine phosphorylation and with the development of a distinct pattern of motility (hyperactivated motility). Capacitated sperm are also able to respond to chemotactic stimuli from the egg and to undergo acrosomal exocytosis. All these processes are regulated by intrinsic sperm factors, but they also depend on certain stimuli present in the male and female reproductive tracts (Yanagimachi 1994, Wassarman et al. 2001, Eisenbach \& Giojalas 2006, Vazquez-Levin \& Marín-Briggiler 2009).

In previous studies done in the human model, we described the presence of FGF2 and functional FGFRs in the testis and sperm, and our results suggest that this system is involved in the regulation of human spermatogenesis and sperm motility (Saucedo et al. 2015, Garbarino Azúa et al. 2017). Moreover, human sperm incubation with recombinant FGF2 (rFGF2) led to an increase in the percentage of motile cells (Saucedo et al. 2015) and to an improvement in sperm recovery in a selection technique, indicating the potential use of this compound in the human clinical practice (Garbarino Azúa et al. 2017).

The present work was aimed to further advance in the knowledge of the FGF2/FGFRs system in the modulation of the reproductive function in mammals, using the murine model. Our objectives were (1) to evaluate the presence of FGF2 in tissues of the female reproductive tract, (2) to describe the expression and localization of FGFRs in the sperm cells and (3) to determine the effect of incubation with rFGF2 upon different sperm parameters.

\section{Materials and methods \\ Reagents and antibodies}

All reagents were of tissue culture grade and molecular biology quality, purchased from Sigma Chemical Co., GE-Amersham Pharmacia (Piscataway, NJ, USA) and ThermoLife Technologies (Carlsbad, CA, USA), unless indicated.

The following polyclonal antibodies and their corresponding blocking peptides (P) were used: anti-FGF2 (sc-79 and sc-79 P), anti-FGFR1 (sc-121 and sc-121 P), anti-FGFR2 (sc-122 and sc-122 P), anti-FGFR3 (sc-123 and sc-123 P) and anti-FGFR4 (sc-9006) (Santa Cruz Biotechnology Inc.). No blocking peptide was commercially available to anti-FGFR-4. Other antibodies used were rabbit immunoglobulin G (IgG) (Sigma), anti-pTyr monoclonal (clone 4G10; Upstate Biotechnology, Lake Placid, NY, USA), anti-tubulin (Sigma), anti-rabbit
IgG-conjugated with horseradish peroxidase (HRP) (Sigma), with Alexa Fluor 488 (A-11008) (Life Technologies) and with Cy3 (Chemicon-Millipore, Billerica, MA, USA), and anti-mouse conjugated with HRP (Vector Laboratories, Inc., Burlingame, CA, USA).

The rFGF2 was produced in a bacterial expression system (gently provided by Dr. Baldi and Dr. Góngora, IBYME) and was previously shown to activate FGFRs in human sperm (Saucedo et al. 2015). BGJ398 (NVP-BGJ398; Selleck Chemicals LLC, Houston, TX, USA), a selective inhibitor of FGFR tyrosine kinase activity (Guagnano et al. 2011), was used when indicated.

\section{Animals and experimental procedures}

Hybrid F1 (C57BI/6 x Balb/c) mature (2- to 6-month old) mice were used. Animals were maintained at $23^{\circ} \mathrm{C}$ with a $12-\mathrm{h}$ light:12-h darkness cycle. Experiments were performed in strict accordance with the Guide for Care and Use of Laboratory Animals approved by the National Institutes of Health. Experimental procedures were reviewed and approved by the Ethics Committee of the Instituto de Biología y Medicina Experimental (Ref: CE 010-2/2013) and the Institutional Animal Care and Use Committee (Approval number 022/2016).

To analyze the expression of FGF2 in tissues of the female reproductive tract, 2- to 4-month-old females were used. The estrous cycle stage was determined every morning by the analysis of vaginal smears as previously described (Caligioni 2009). The uteri and oviducts of females in estrous were removed and stored at $-80^{\circ} \mathrm{C}$ for protein extraction or processed immediately for indirect immunofluorescence. To obtain the cumulus oophorus-oocyte complexes (COCs), females were stimulated with hormones. Animals were treated with an i.p. injection of equine chorionic gonadotrophin (eCG; 5 IU; Syntex SA, Buenos Aires, Argentina), followed by an i.p. injection of human chorionic gonadotrophin (hCG; $5 \mathrm{IU}$, Sigma) $48 \mathrm{~h}$ later. After 12-14h, females were killed, the oviducts were removed and the COCs were collected.

The testes were obtained and stored at $-80^{\circ} \mathrm{C}$ for protein extraction or processed immediately for immunohistochemistry. To recover sperm cells, both cauda epididymides from a mouse were collected, dissected and placed in $400 \mu \mathrm{L}$ of culture medium (Fraser \& Drury 1975) for $10 \mathrm{~min}$ to allow the release of motile cells (swim-out procedure). When indicated, sperm (at a concentration of $1-10 \times 10^{6} / \mathrm{mL}$ ) were resuspended in medium supplemented with $0.3 \%$ bovine serum albumin (BSA) and incubated at $37^{\circ} \mathrm{C}$ in an atmosphere of $5 \% \mathrm{CO}_{2}$ in air to promote capacitation.

\section{Protein extracts, SDS-PAGE and Western immunoblotting}

To obtain the protein extracts from uterus, oviduct and testis, small tissue sections were placed in $0.5 \mathrm{~mL}$ of homogenization buffer containing $0.1 \%$ SDS, $1 \%$ Triton $\mathrm{X}-100,1 \%$ sodium deoxycholate in PBS supplemented with protease inhibitors. Tissues were disaggregated with a homogenizer (5 pulses of $3 \mathrm{~s}$ at maximum potency) and subjected to centrifugation $\left(15,000 \mathrm{~g}\right.$ for $5 \mathrm{~min}$ at $\left.4^{\circ} \mathrm{C}\right)$. 
The supernatants were recovered, supplemented with Laemmli sample buffer, heated at $100^{\circ} \mathrm{C}$ for $5 \mathrm{~min}$ and stored at $-70^{\circ} \mathrm{C}$ until used. To obtain the sperm protein extracts, a suspension of motile cells was centrifuged for $5 \mathrm{~min}$ at $600 \mathrm{~g}$, the sperm pellets were resuspended with Laemmli sample buffer, heated, centrifuged and the supernatants were recovered. Protein concentration was determined using the Bradford method. Samples were supplemented with 5\% 2-mercaptoethanol, boiled for $10 \mathrm{~min}$ and subjected to SDS-PAGE in 8 or $15 \%$ polyacrylamide gels and Western immunoblotting. Anti-FGF2, anti-FGFR antibodies or rabbit IgG was used at $2 \mu \mathrm{g} / \mathrm{mL}$ and HRP-conjugated secondary antibody was used at $0.5 \mu \mathrm{g} / \mathrm{mL}$. As a control, each primary antibody was pre-incubated with its blocking peptide at five-fold (by weight) excess following the supplier's recommendations. To analyze protein tyrosine phosphorylation, sperm were incubated under capacitating conditions in the presence or absence of rFGF2 for different periods of time. Proteins were extracted, subjected to SDSPAGE in $10 \%$ polyacrylamide gels and developed with antipTyr, anti-tubulin $(0.2 \mu \mathrm{g} / \mathrm{mL})$ and anti-mouse HRP antibody (Marín-Briggiler et al. 1999). The reactive bands were detected by enhanced chemiluminiscence (ECL kit, GE-Amersham) using standard procedures.

\section{Immunohistochemistry and immunocytochemistry}

Uteri and oviducts were dissected, washed and immediately embedded in Optimum Cutting Temperature compound (Biopack, Buenos Aires, Argentina). Sections of $8 \mu \mathrm{m}$ were cut with a cryostat and kept at $-80^{\circ} \mathrm{C}$ until processed. Slides were fixed in $4 \%$ formaldehyde in PBS for $20 \mathrm{~min}$, immersed for $30 \mathrm{~min}$ in a $150 \mathrm{mM}$ glycine solution and incubated for $45 \mathrm{~min}$ with blocking solution $(0.1 \mathrm{M}$ glycine, $1 \%$ normal goat serum, $0.5 \%$ BSA, $0.01 \%$ Triton $\mathrm{X}-100$ in PBS). Slides were then incubated overnight at $4{ }^{\circ} \mathrm{C}$ with anti-FGF2 $(4 \mu \mathrm{g} / \mathrm{mL}$ in PBS with $4 \%$ BSA). As a control, the primary antibody was pre-incubated with its blocking peptide at five-fold (by weight) excess following the supplier's recommendations. Following 3 washes with $0.1 \%$ Triton X-100 in PBS, tissues were incubated for $1 \mathrm{~h}$ with anti-rabbit IgG labeled with Alexa Fluor 488 $(10 \mu \mathrm{g} / \mathrm{mL}$ in PBS).

COCs were fixed with $2 \%$ paraformaldehyde in PBS for $1 \mathrm{~h}$, washed with PBS and incubated in blocking solution for $2 \mathrm{~h}$. Then, they were exposed to anti-FGF2 $(8 \mu \mathrm{g} / \mathrm{mL}$ in $4 \%$ BSA in PBS), pre-incubated or not with the blocking peptide. Following 3 washes with PBS containing $0.3 \%$ BSA and $0.02 \%$ Tween, COCs were incubated for $1 \mathrm{~h}$ with anti-rabbit IgG labeled with Alexa Fluor $488(20 \mu \mathrm{g} / \mathrm{mL})$. Tissues and COCs were counterstained with propidium iodide (PI, Sigma), slides were mounted with Vectashield (Vector Laboratories, Inc) and were observed with a laser confocal microscope (C1, Nikon). Images were acquired with an objective Plan Apo 40×/0.95 (excitation/emission: $488 \mathrm{~nm} / 515-530 \mathrm{~nm}$ and $544 \mathrm{~nm} / 570 \mathrm{LP}$ ) and analyzed using standard procedures for fluorescent imaging.

Small portions of mouse testis were fixed and processed for immunohistochemistry, using anti-FGFR antibodies or rabbit IgG $(4 \mu \mathrm{g} / \mathrm{mL})$ and the LSAB + System HRP kit (K0690, Dako) as previously described (Marín-Briggiler et al. 2008).
To determine the specificity of anti-FGFRs, they were preincubated with the corresponding blocking peptides. Specimens were counterstained with hematoxylin, dehydrated and mounted. Sections were evaluated at $\times 600$ magnification using an Eclipse E800 microscope (Nikon Instruments Inc.). The expression of FGFRs was assessed in Sertoli and germ cells at different stages of the spermatogenic cycle (Russell et al. 1990).

Sperm (non-capacitated or incubated under capacitating conditions for $90 \mathrm{~min})$ were fixed with formaldehyde $(2 \%$ in PBS) for $4 \mathrm{~min}$ and processed for staining with anti-FGFR antibodies, rabbit $\operatorname{lgG}(20 \mu \mathrm{g} / \mathrm{mL})$ or the primaries antibodies previously incubated with the blocking peptides and Cy3conjugated secondary antibody. Sperm were also stained with the lectin Pisum sativum agglutinin labeled with FITC (FITCPSA, Sigma; $50 \mu \mathrm{g} / \mathrm{mL}$ in PBS) to assess the acrosomal status of each cell. A green fluorescent signal on the acrosomal region was indicative of an intact acrosome. At least 200 sperm in duplicate samples were evaluated at $\times 1000$ magnification.

\section{Computer-assisted sperm analysis}

To analyze the effect of rFGF2 on sperm motility, samples were incubated for 30, 60 and 90 min with different concentrations of rFGF2. The rFGF2 concentrations used in the present study were similar to those reported with somatic cells (Kubota \& Ito 2000, Kamura et al. 2010) and with human sperm (Saucedo et al. 2015). When indicated, sperm were incubated for $15 \mathrm{~min}$ with the FGFR inhibitor (BGJ398, $0.1 \mu \mathrm{M}$ (Saucedo et al. 2015)) prior to the incubation with rFGF2 in capacitating conditions.

Sperm motility parameters were evaluated using the Sperm Class Analyzer system (SCA v.6.2.0.1., Microptic SL, Barcelona, Spain) that acquires 60 frames per s (total frames analyzed: 30). A microscope with a temperature-controlled stage was used to maintain sperm at constant $37^{\circ} \mathrm{C}$. For each sample, at least seven microscopic fields were analyzed and more than 300 sperm were evaluated. The following parameters were assessed: curvilinear velocity $(\mathrm{VCL}, \mu \mathrm{m} / \mathrm{s})$, straightline velocity $(\mathrm{VSL}, \mu \mathrm{m} / \mathrm{s})$, average path velocity $(\mathrm{VAP}, \mu \mathrm{m} / \mathrm{s})$, linearity (LIN, \%), amplitude of lateral head displacement $(\mathrm{ALH}, \mu \mathrm{m})$, straightness (STR, \%), beat cross frequency (BCF, $\mathrm{Hz}$ ) and wobble (WOB, \%). Sperm motility was measured and classified as follows: rapid progressive (VCL $\geq 45 \mu \mathrm{m} / \mathrm{s}$; STR $\geq 50 \%$ ), medium progressive ( $\mathrm{VCL} \geq 15 \mu \mathrm{m} / \mathrm{s}$; STR $\geq 50 \%$ ), in situ (VCL $<15 \mu \mathrm{m} / \mathrm{s}$; VAP $\geq 5 \mu \mathrm{m} / \mathrm{s}$ ) and immotile (VAP $<5 \mu \mathrm{m} / \mathrm{s}$ ). Percentages of total (rapid progressive + medium progressive + in situ) and progressive (rapid+medium progressive) motility were recorded. Sperm were considered hyperactivated when presenting VCL $\geq 271 \mu \mathrm{m} / \mathrm{s}$, LIN $<50 \%$ and $\mathrm{ALH} \geq 3.5 \mu \mathrm{m}$.

\section{Sperm accumulation assay}

To determine whether rFGF2 stimulates sperm accumulation, the sperm selection assay (SSA) was used (Gatica et al. 2013). The device consists of two wells (W1 and W2) connected by a $2 \mathrm{~mm}$-length tube, with a hermetic closing system. An aliquot of 1-h capacitated motile sperm (at a concentration of $3 \times 10^{6} / \mathrm{mL}$ ) was placed in W1, while rFGF2 was loaded in W2, 
forming an ascending gradient of the ligand in the connecting tube between the wells. Different concentrations of rFGF2 were tested. Culture medium or $100 \mathrm{pM}$ progesterone ( $\mathrm{Prg}$, Sigma) was placed in W2 as negative and positive controls respectively (Guidobaldi et al. 2017). After $20 \mathrm{~min}$ of incubation at $37^{\circ} \mathrm{C}, 5 \% \mathrm{CO}_{2}$ in air, the content of W2 was recovered and sperm concentration was determined using a Neubauer hemocytometer. The percentage of accumulated sperm was calculated as the number of sperm recovered from W2 after the assay, divided by the number of motile sperm initially placed on W1. The result was multiplied by 100 and each determination was done in duplicate. To discriminate whether sperm accumulation in W2 was due to chemotaxis, chemokinesis (an increase of sperm speed) or trapping (e.g. induced by hyperactivation), the SSA was repeated with homogeneous distribution of rFGF2 in the device (the ligand was present in W1 with the sperm suspension, in the connecting tube and in W2).

\section{Intracellular $\mathrm{Ca}^{2+}$ measurements}

Intracellular $\mathrm{Ca}^{2+}$ levels were measured by flow cytometry as described (Brukman et al. 2016). Sperm were incubated in capacitating conditions with different concentrations of rFGF2 for a total of 30 and $60 \mathrm{~min}$, and $2 \mu \mathrm{M}$ Fluo-4 AM (Invitrogen), diluted in $10 \%$ Pluronic F-127 (Invitrogen) was added in the last $30 \mathrm{~min}$. Samples were centrifuged for $3 \mathrm{~min}$ at $600 \mathrm{~g}$ to remove the excess of probe, resuspended in BSA-free medium and exposed to $2.5 \mu \mathrm{g} / \mathrm{mL}$ PI. Fluorescence was detected using a BD FACSCantoTM II analyzer following the manufacturer's indications. Data analysis was performed by the Flowjo 7.6 software (Flowjo LLC, Ashland, OR, USA). Results are shown as mean fluorescence intensity for Fluo-4 AM obtained from at least 10,000 live (PI-negative) sperm. The histograms of a representative experiment were also shown.

\section{Analysis of acrosomal exocytosis}

The effect of rFGF2 on acrosomal exocytosis was determined in sperm incubated under capacitating conditions for $90 \mathrm{~min}$ in the presence of different concentrations of rFGF2 $(0-100 \mathrm{ng} / \mathrm{mL})$. Cells were subjected to Coomassie brilliant blue staining as previously described (Busso et al. 2007) and were analyzed under 400× magnification using a Nikon microscope (Nikon Instruments Inc.). At least 200 sperm cells were evaluated. Sperm were scored as acrosome intact when a bright blue staining was found in the dorsal region of the head and as acrosome-reacted when no labeling was observed in this area.

\section{Statistical analysis}

Data were expressed as mean \pm S.E.M.. To assume normal distribution, percentages were expressed as ratios and subjected to the arcsine square root transformation. Results were compared by one-way ANOVA and the Dunnett's multiple comparison test. Statistical analyses were carried out using the GraphPad InStat program (GraphPad Software). Differences were considered significant at a level of $P<0.05$.

\section{Results}

\section{Presence and localization of FGF2 in the female reproductive tract}

The expression of FGF2 protein in the mouse uterus and oviduct was analyzed by Western immunoblotting. Results showed the presence of three FGF2 isoforms (of 18,21 and $23 \mathrm{kDa}$ ) in protein extracts of these tissues (Fig. 1A). Immunofluorescence studies indicated that FGF2 is expressed in the epithelial cells of the uterus, isthmus and ampulla (Fig. 1B). In addition, a mild immunoreactivity was found in muscle cells of the isthmus. FGF2 was also detected in the cytoplasm of

A
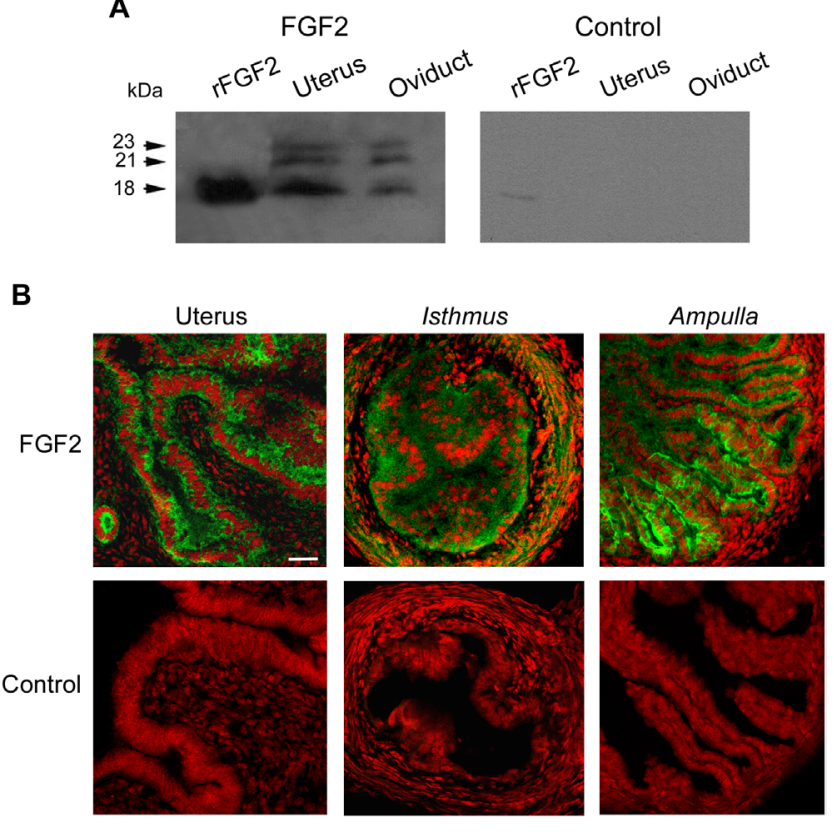

C
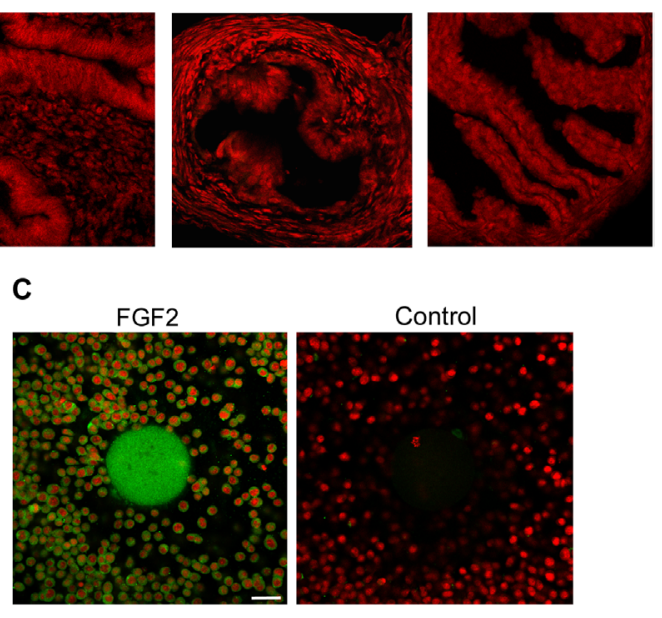

Figure 1 Presence and localization of FGF2 in murine female reproductive tract. (A) Protein extracts from uterus $(60 \mu \mathrm{g})$ and oviduct $(120 \mu \mathrm{g})$ were subjected to SDS-PAGE, followed by Western immunoblotting using anti-FGF2. rFGF2 (5 ng) was included. As a control, the primary antibody was pre-incubated with its blocking peptide. A representative result is shown. (B) Sections of uterus, isthmus and ampulla were subjected to immunofluorescence studies using anti-FGF2 antibody and anti-mouse labeled with Alexa Fluor 488. As a control, the primary antibody was pre-incubated with its blocking peptide. Cell nuclei were counterstained with PI. Bar: $20 \mu \mathrm{m}$. Typical results are shown. (C) COCs were recovered from the ampulla and subjected to immunofluorescence studies using anti-FGF2 antibody and anti-mouse labeled with Alexa Fluor 488. Cell nuclei were counterstained with PI. Bar: $20 \mu \mathrm{m}$. 
the oocyte and cumulus oophorus cells (Fig. 1C). The staining was specific, since no signal was observed when the primary antibody was pre-incubated with the blocking peptide as a control (Fig. 1A, B and C).

\section{Presence and localization of FGFR proteins in mouse sperm}

Previous studies reported the expression of FGFR1 in mouse sperm (Cotton et al. 2006); however, there is no evidence on the expression of other FGFRs in these cells. We analyzed the presence of FGFR1, FGFR2, FGFR3 and FGFR4 in mouse sperm by Western immunoblotting using specific antibodies. A protein form of approximately $100 \mathrm{kDa}$ was detected with antiFGFR1 and anti-FGFR3. Forms of 127 and $116 \mathrm{kDa}$ were found with anti-FGFR2 and anti-FGFR4, respectively (Fig. 2A). Such bands were not observed when the antibodies against FGFR1, FGFR2 and FGFR3 were preincubated with their corresponding blocking peptides or when rabbit IgG was used as control (Fig. 2A).

Indirect immunofluorescence studies revealed the localization of FGFR1, FGFR2, FGFR3 and FGFR4 in the flagellum (middle and principal piece) of all non-

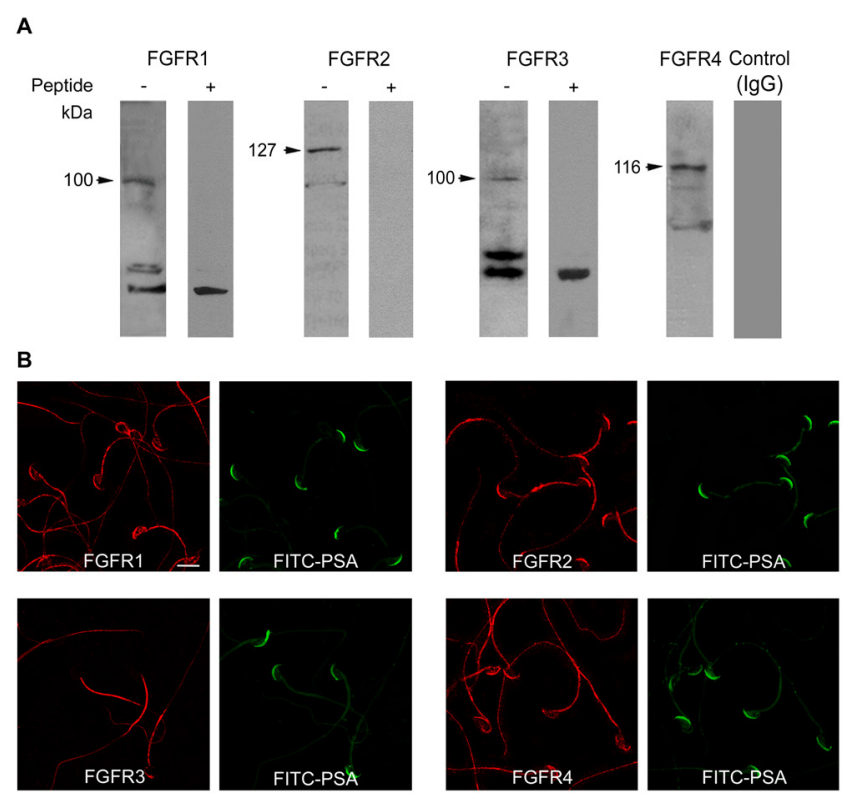

Figure 2 Presence and localization of FGFRs in mouse sperm. (A) Detection of sperm FGFR protein forms using Western immunoblotting. Protein extracts from mouse sperm were subjected to SDS-PAGE and developed using anti-FGFR antibodies. As a control, each primary antibody was pre-incubated with its blocking peptide, or rabbit IgG was used. The estimated molecular weights of the protein bands are indicated on the left. The experiments were performed at least three times obtaining similar results. Typical results are shown. (B) Immunolocalization of FGFRs in mouse sperm. Sperm cells were stained with anti-FGFR1, FGFR2, FGFR3 or FGFR4 and a secondary antibody labeled with Cy3 (left images). Sperm were also stained with FITC-PSA to assess their acrosomal status, and the corresponding fields are shown (right images). Bar: $10 \mu \mathrm{m}$. capacitated sperm. FGFR immunoreactivity was also observed in the acrosomal region of non-capacitated, acrosome-intact sperm (for FGFR1: $83 \pm 3 \%$, for FGFR2: $93 \pm 1 \%$, for FGFR3: $35 \pm 6 \%$ and for FGFR4: $83 \pm 1 \%$ sperm, $n=5$ ) (Fig. 2B). After incubation under capacitating conditions, sperm maintained FGFR localization in the flagellum; however, there was a reduction of FGFR signal in the acrosomal region, even when sperm had intact acrosomes (for FGFR1: $14 \pm 1 \%$, for FGFR2: $38 \pm 3 \%$, for FGFR3, $0 \pm 0 \%$ and for FGFR4: $16 \pm 5 \%$ sperm) (Supplementary Fig. 1, see section on supplementary data given at the end of this article). FGFR immunodetection was specific, as no staining was observed when the antibodies were pre-incubated with the respective peptides or when primary antibodies were replaced by rabbit IgG (Supplementary Fig. 2).

\section{Expression and immunodetection of FGFR proteins in mouse testis}

To analyze the testicular origin of sperm FGFRs, we performed Western immunoblotting of testicular protein extracts, as well as immunohistochemical studies on testicular tissue sections. Protein extracts developed with anti-FGFR1 showed a main protein band of $117 \mathrm{kDa}$. Bands of approximately 127, 125 and $116 \mathrm{kDa}$ were detected with anti-FGFR2, FGFR3 and FGFR4, respectively. No immunoreactivity was observed when rabbit IgG was used as a control (Fig. 3A).

Immunohistochemical studies allowed the detailed analysis of FGFR expression in the seminiferous epithelium and in different stages of the spermatogenic cycle. Results showed the localization of the four FGFRs in germ cells, in a stage-dependent manner $(n=3)$. All receptors were immunolocalized in the flagellum of elongating/elongated spermatids (Fig. 3B). In particular, FGFR1 expression was observed in Sertoli and germ cells, mainly in the adluminal compartment. This protein was localized in pachytene spermatocytes, round and elongated spermatids and the staining was stronger in stages VIII-XII in comparison to stages I-VII. FGFR2 immunoreactivity was moderate in Sertoli cells, but intense in the germ cells, with a higher signal in the cytoplasm of elongating spermatids of stages X-XII. Regarding FGFR3, a weak immunostaining was observed in the seminiferous epithelium, with a mild signal in the cytoplasm of elongating spermatids of stages X-XII. The presence of FGFR3 was also detected in the acrosomal region of round and elongating spermatids of stages $\mathrm{VI}-$ XI. A weak staining for FGFR4 was found in germ cells at stages $I-V$ and a moderate signal was detected in the cytoplasm of elongating spermatids (stages X-XII).

\section{Effect of FGF2 in the regulation of sperm physiology}

To determine the role of the FGF2/FGFRs system in sperm physiology, cauda epididymal sperm were 


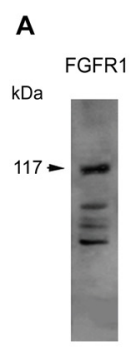

B FGFR1

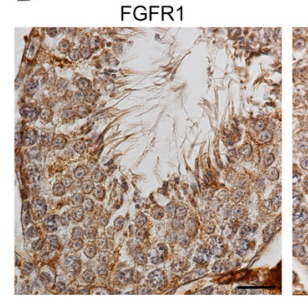

FGFR4
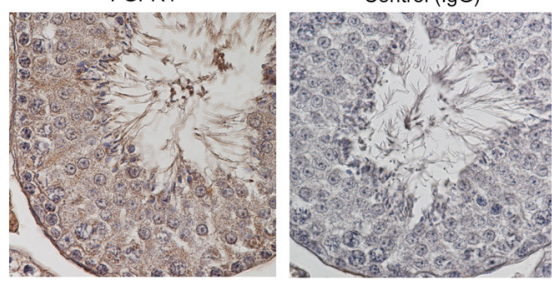

Figure 3 Expression and immunodetection of FGFRs in mouse testis. (A) Detection of sperm FGFR protein forms using Western immunoblotting. Protein extracts from mouse testis were subjected to SDS-PAGE and developed using anti-FGFR antibodies or rabbit IgG as control. The estimated molecular weights of the protein bands are indicated on the left. The experiments were performed at least three times obtaining similar results. Typical results are shown. (B) Immunolocalization of FGFRs in mouse testis. Histological sections were stained with anti-FGFR1, FGFR2, FGFR3 or FGFR4. Rabbit IgC was included as control. The specimens were counterstained with hematoxylin. Images correspond to stages VII or VIII. Arrows indicate immunoreactivity for FGFR3 in spermatid acrosome. Bar: $20 \mu \mathrm{m}$.

incubated with different concentrations of rFGF2 and several parameters were assessed.

Incubation with 0.1 and $1 \mathrm{ng} / \mathrm{mL}$ rFGF2 for 30 min led to a significant increase in total and progressive sperm motility. The effect was mediated by FGFR activation, since the response was abolished when the cells were pre-incubated with the inhibitor BGJ398 (Fig. 4A and B). An enhancement $(P<0.05)$ in velocity parameters $(\mathrm{VCL}$ and VSL) was also observed after exposure to $0.1 \mathrm{ng} / \mathrm{mL}$ rFGF2 for $30 \mathrm{~min}$ (Table 1); however, at this time point, no significant changes were observed in other sperm parameters or in the percentage of hyperactivated cells (Table 1). No effect was detected in the percentages of either total, progressive or hyperactivated motility in sperm incubated with rFGF2 for 60 or 90 min (Table 2).

Next, the effect of rFGF2 on sperm accumulation was evaluated using the SSA. When sperm were exposed to an ascending gradient of $0.1 \mathrm{ng} / \mathrm{mL}$ rFGF2 in the connecting tube, a significant accumulation of cells was observed in W2 well (Fig. 5A). The percentage of
A
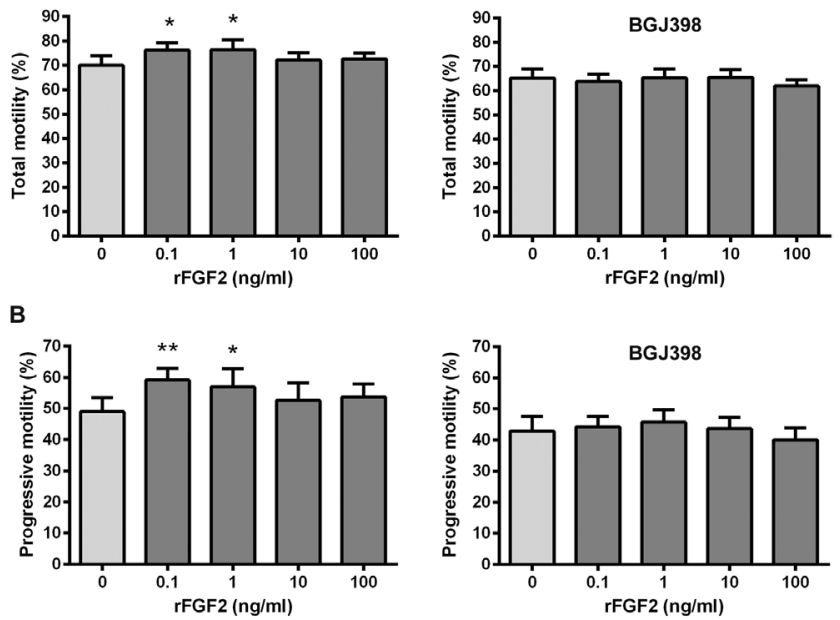

Figure 4 Effect of sperm incubation with rFGF2 on sperm motility. Sperm were incubated with $0,0.1,1,10$ and $100 \mathrm{ng} / \mathrm{mL}$ rFGF2 in the absence or in the presence of $0.1 \mu \mathrm{M}$ BGJ398 (left and right, respectively) and subjected to computer-assisted sperm analysis. (A) Percentages of total motility (rapid progressive + medium progressive + in situ). (B) Percentages of progressive motility (rapid + medium progressive). Results are expressed as mean \pm S.E.M., $n=6$ without BGJ398 and $n=8$ with BGJ398. $* P<0.05, * * P<0.01$ compared with $0 \mathrm{ng} / \mathrm{mL}$ rFGF2.

accumulated sperm was similar to that obtained with Prg. To distinguish if sperm accumulation was due to an effect of rFGF2 on chemotaxis, chemokinesis or trapping, the assay was repeated in medium with a homogeneous concentration of $0.1 \mathrm{ng} / \mathrm{mL}$ rFGF2. Results also showed a significant sperm accumulation under this condition (Fig. 5B), suggesting that the accumulation was not due to a chemotactic response, but to a chemokinetic effect of rFGF2 on the sperm cells. The possibility that rFGF2 has a trapping effect (i.e. hyperactivation) was discarded since under homogeneous rFGF2 distribution, a reduced sperm accumulation would have been expected in W2 well (Giojalas et al. 2015).

The effect of sperm incubation with rFGF2 upon capacitation-related events was also determined. Sperm incubated for $30 \mathrm{~min}$ with 1, 10 and $100 \mathrm{ng} / \mathrm{mL}$ rFGF2 depicted a significant increase in intracellular $\mathrm{Ca}^{2+}$ levels. Such effect was not observed after 60-min incubation with rFGF2 (Fig. 6A and Supplementary Fig. 3). In sperm exposed to rFGF2 for 30, 60 or 90 min, no changes in protein tyrosine phosphorylation were detected in comparison to the control (Fig. 6B). However, after $90-\mathrm{min}$ incubation with $0.1,1$ or $10 \mathrm{ng} / \mathrm{mL} \mathrm{rFGF} 2$ a significant increase in the percentage of acrosomereacted sperm was observed (Fig. 6C).

\section{Discussion}

In the present study, we first aimed to describe the expression of FGF2 in the mouse female reproductive 
Table 1 Kinematics and percentage of hyperactivated motility of mouse sperm incubated for 30 min with rFGF2.

\begin{tabular}{|c|c|c|c|c|c|}
\hline & 0ng/mL rFGF2 & $0.1 \mathrm{ng} / \mathrm{mL}$ rFGF2 & $1 \mathrm{ng} / \mathrm{mL}$ rFGF2 & $10 \mathrm{ng} / \mathrm{mL}$ rFGF2 & $100 \mathrm{ng} / \mathrm{mL}$ rFGF2 \\
\hline $\operatorname{VCL}(\mu \mathrm{m} / \mathrm{s})$ & $127 \pm 11$ & $146 \pm 14^{*}$ & $133 \pm 12$ & $120 \pm 16$ & $123 \pm 13$ \\
\hline $\operatorname{VSL}(\mu \mathrm{m} / \mathrm{s})$ & $36 \pm 4$ & $45 \pm 6^{*}$ & $34 \pm 4$ & $32 \pm 5$ & $34 \pm 5$ \\
\hline $\operatorname{VAP}(\mu \mathrm{m} / \mathrm{s})$ & $63 \pm 4$ & $74 \pm 1$ & $60 \pm 6$ & $60 \pm 6$ & $60 \pm 3$ \\
\hline LIN $(\%)$ & $22 \pm 1$ & $24 \pm 1$ & $22 \pm 1$ & $23 \pm 1$ & $23 \pm 1$ \\
\hline $\mathrm{ALH}(\mu \mathrm{m})$ & $3 \pm 0$ & $3 \pm 0$ & $3 \pm 0$ & $3 \pm 0$ & $3 \pm 0$ \\
\hline STR $(\%)$ & $47 \pm 1$ & $50 \pm 2$ & $48 \pm 2$ & $48 \pm 2$ & $47 \pm 2$ \\
\hline $\mathrm{BCF}(\mathrm{Hz})$ & $8 \pm 0$ & $9 \pm 0$ & $8 \pm 0$ & $8 \pm 1$ & $8 \pm 0$ \\
\hline WOB $(\%)$ & $42 \pm 1$ & $44 \pm 1$ & $41 \pm 1$ & $43 \pm 1$ & $42 \pm 1$ \\
\hline Motility (\%) & $4 \pm 1$ & $7 \pm 2$ & $5 \pm 2$ & $3 \pm 1$ & $3 \pm 1$ \\
\hline
\end{tabular}

Computer-assisted sperm analysis of sperm incubated with $0,0.1,1,10$ or $100 \mathrm{ng} / \mathrm{mL} \mathrm{rFGF}$. Parameters measured were curvilinear velocity (VCL), straight-line velocity (VSL), average path velocity (VAP), linearity (LIN), amplitude of lateral head displacement (ALH), straightness (STR), beat cross frequency (BCF) and wobble (WOB). Results are expressed as mean \pm S.E.M., $n=6$.

$* P<0.05$ compared with $0 \mathrm{ng} / \mathrm{mL}$ rFGF2.

tract. Western immunoblotting analysis allowed the detection of the three FGF2 isoforms, including the $18-\mathrm{kDa}$ secreted form, in the uterus and oviduct. By immunofluorescence, FGF2 was mainly localized in the epithelial cells of these tissues, as well as in the egg and cumulus oophorus cells. Previous reports described FGF2 expression in tissues of the bovine and primate female reproductive tracts, and its secretion by oviduct epithelial cells, mainly in the pre-ovulatory stage (Gabler et al. 1997, 1998). FGF2 secretion has also been found in human COCs (Malamitsi-Puchner et al. 2001, Ben-Haroush et al. 2005). Such studies focused in the proliferative, mitogenic and angiogenic effects of FGF2 on cells of these tissues; however, the role of the FGF2 present in the female reproductive tract on the regulation of sperm physiology remains unknown.

To determine the relevance of the FGFs/FGFRs system in the regulation of the mouse male gamete, we initially determine the presence and localization of FGFRs in the sperm cells. By Western immunoblotting, the 4 FGFRs were detected in sperm extracts. Using anti-FGFR1 and anti-FGFR2 antibodies, bands of approximately 100 and $127 \mathrm{kDa}$, respectively, were found. These bands were similar to those previously reported in mouse testis (Cotton et al. 2006, Li et al. 2014). Regarding FGFR3, a protein form of approximately $100 \mathrm{kDa}$ was observed, in agreement to that identified in human sperm (Saucedo et al. 2015). Anti-FGFR4 revealed a main protein form of $116 \mathrm{kDa}$, also found in mouse testicular extracts.
The lower molecular weight protein bands obtained for FGFR1 and FGFR3 in sperm in comparison to testicular extracts could be attributed to protein degradation during processing. The same antibodies were used in immunocytochemical studies, and the 4 FGFRs were localized in the flagella of both non-capacitated and capacitated sperm. FGFR1, FGFR2 and FGFR4 were also detected in the acrosomal region of the majority of noncapacitated sperm, but a loss in their immunoreactivity was observed in capacitated cells, as reported for many sperm proteins (Yanagimachi 1994).

In order to determine the testicular origin of the sperm FGFRs, we analyzed the localization of FGFRs in the seminiferous epithelium. The expression of the 4 FGFRs was detected in the germ and Sertoli cells of the mouse testis, in a stage-specific manner, suggesting that FGF signaling is involved in the regulation of murine spermatogenesis. Immunostaining with antiFGFRs revealed a stronger signal in the adluminal compartment compared to the basal compartment of the seminiferous epithelium, due to lower FGFR expression in the spermatogonia and a higher expression in more differentiated germ cells. In particular, a strong immunoreactivity for FGFRs 1-4 was found in the flagellum of elongating and elongated spermatids. The expression of FGFRs in the testis has been previously described in several mammalian species (Cotton et al. 2008), including the human (Steger et al. 1998, Saucedo et al. 2015). Our results are in accordance to a detailed

Table 2 Mouse sperm motility after incubation for 60 and $90 \mathrm{~min}$ with rFGF2.

\begin{tabular}{|c|c|c|c|c|c|}
\hline & 0ng/mL rFGF2 & $0.1 \mathrm{ng} / \mathrm{mL}$ rFGF2 & $1 \mathrm{ng} / \mathrm{mL}$ rFGF2 & $10 \mathrm{ng} / \mathrm{mL}$ rFGF2 & $100 \mathrm{ng} / \mathrm{mL}$ rFGF2 \\
\hline \multicolumn{6}{|l|}{$60 \min$} \\
\hline Total motility $(\%)$ & $65 \pm 2$ & $67 \pm 3$ & $68 \pm 4$ & $68 \pm 3$ & $67 \pm 4$ \\
\hline Progressive motility (\%) & $46 \pm 2$ & $47 \pm 4$ & $48 \pm 4$ & $49 \pm 4$ & $47 \pm 6$ \\
\hline Hyperactivated motility (\%) & $7 \pm 3$ & $7 \pm 2$ & $7 \pm 3$ & $8 \pm 2$ & $8 \pm 3$ \\
\hline \multicolumn{6}{|l|}{$90 \mathrm{~min}$} \\
\hline Total motility $(\%)$ & $67 \pm 3$ & $69 \pm 2$ & $68 \pm 2$ & $69 \pm 2$ & $66 \pm 1$ \\
\hline Progressive motility (\%) & $47 \pm 4$ & $49 \pm 3$ & $45 \pm 2$ & $46 \pm 2$ & $43 \pm 3$ \\
\hline Hyperactivated motility (\%) & $8 \pm 2$ & $6 \pm 2$ & $5 \pm 2$ & $5 \pm 1$ & $6 \pm 2$ \\
\hline
\end{tabular}

Computer-assisted sperm analysis of sperm incubated for 60 and 90 min with 0, 0.1, 1, 10 or $100 \mathrm{ng} / \mathrm{mL}$ rFGF2. Results are expressed as mean \pm S.E.M., $n=7$. At each time point, no significant differences were found for each parameter among the conditions. 

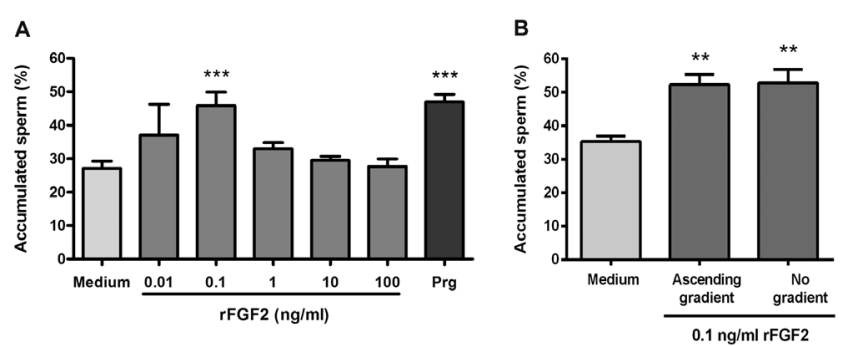

Figure 5 Effect of rFGF2 on sperm accumulation. (A) Sperm were subjected to the sperm selection assay, with different concentrations of rFGF2 in W2 (ascending gradient), or with culture medium and $\mathrm{Prg}$, as negative and positive controls, respectively. (B) Sperm were also exposed to an ascending gradient of $0.1 \mathrm{ng} / \mathrm{mL} \mathrm{rFGF} 2$ or to homogeneous distribution (no gradient) of the recombinant protein. Results are expressed as mean \pm S.E.M., $n=4 .{ }^{* *} P<0.01$, ${ }^{* * *} P<0.001$ compared with Medium.

study describing the presence and localization of the four FGFRs in the fetal, immature and adult rat testes and that these receptors have preferential localization in the adluminal compartment (Cancilla et al. 1998). In addition, the presence of transcripts of several FGFR isoforms (mainly FGFR1c, FGFR2c, FGFR3c and FGFR4) has been reported in the adult mouse testis (Fon Tacer et al. 2010). FGFR proteins have been found in the mouse developing gonad (Lai et al. 2016), and the signaling mediated by FGFR1 and FGF8 has been involved in the maintenance of undifferentiated spermatogonia (Hasegawa \& Saga 2014). Moreover, the role of testicular FGFRs has been analyzed using some models of transgenic mice. On one hand, it has been described that mice expressing a dominant-negative variant of FGFR1 in the male haploid germ cells are subfertile, show diminished sperm production and alterations in sperm capacitation, suggesting the relevance of this receptor in sperm physiology (Cotton et al. 2006). On the other hand, germ-cell-specific conditional knockout mice for FGFR1 or FGFR2 showed normal fertility (Li et al. 2014) and animals lacking FGFR3 or FGFR4 depicted no apparent fertility defects (Deng et al. 1996, Weinstein et al. 1998, Yu et al. 2000). However, in these knock-out animals, a possible functional redundancy with other FGFRs cannot be ruled out.

Considering that mouse sperm showed flagellar localization of FGFRs, it was of interest to analyze the effect of rFGF2 upon sperm motility. Sperm exposure to the recombinant protein led to a significant increase in the percentage of total and progressive motility, in coincidence with the results found in human sperm (Saucedo et al. 2015). While in the murine model, the effect was observed with 0.1 and $1 \mathrm{ng} / \mathrm{mL}$ rFGF2, an enhancement in human sperm motility was obtained with 10 and $100 \mathrm{ng} / \mathrm{mL}$ rFGF2. The differences could be attributed to differences in the physiology of sperm from both species, mainly due to the origin of the cells (epididymal mice sperm vs ejaculated human sperm). When mouse sperm were subjected to the SSA,

Reproduction (2018) 156 163-172

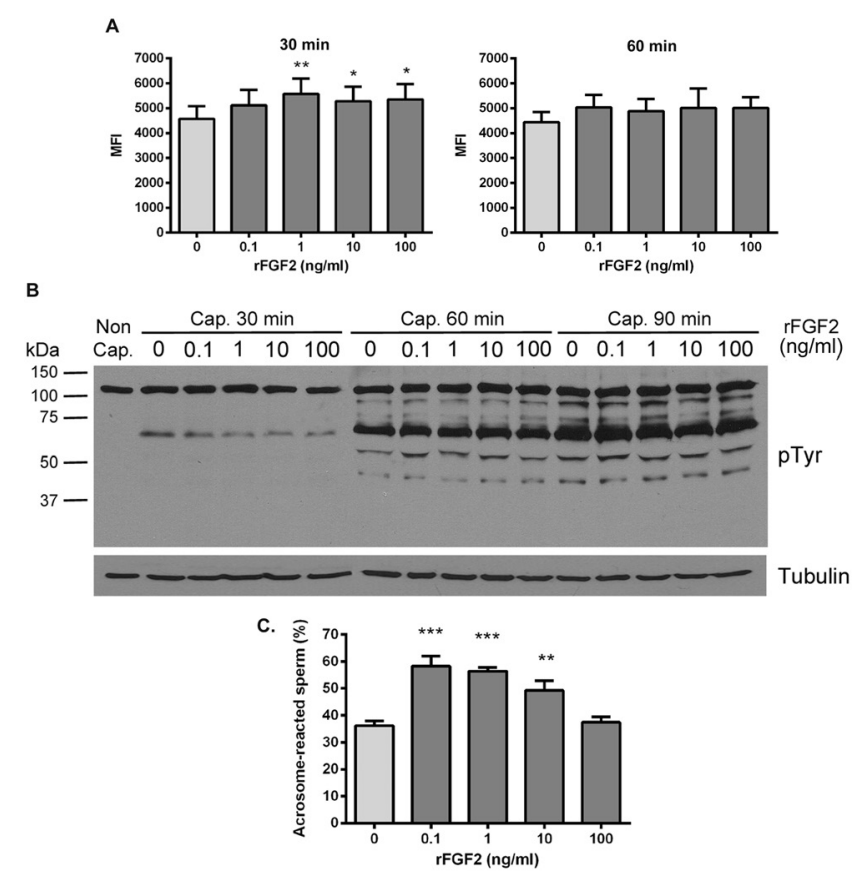

Figure 6 Effect of incubation with rFGF2 on sperm capacitationrelated events. (A) Intracellular $\mathrm{Ca}^{2+}$ levels evaluated by flow cytometry. Sperm were incubated with rFGF2 for 30 and $60 \mathrm{~min}$ and the mean fluorescence intensity (MFI) of Fluo-4 AM was measured in live sperm (PI negative). Results are expressed as mean \pm S.E.M., $n=7$. ${ }^{*} P<0.05,{ }^{*} P<0.01$ compared with $0 \mathrm{ng} / \mathrm{mL} \mathrm{rFGF} 2$. (B) Protein tyrosine phosphorylation in non-capacitated sperm (Non-Cap.) or in cells incubated with rFGF2 for 30, 60 and 90 min (Cap.). Sperm protein extracts were subjected to SDS-PAGE and Western immunoblotting using anti-phosphotyrosine antibody (pTyr) or anti-tubulin as a control. The molecular weight markers are shown on the left. The experiment was performed three times, obtaining similar results. A typical result is shown. (C) Acrosomal exocytosis in sperm exposed to rFGF2. Sperm were incubated with rFGF2 for $90 \mathrm{~min}$, processed and stained with Coomassie brilliant blue, and the percentage of acrosome-reacted cells was evaluated. Results are expressed as mean \pm S.E.M., $n=5 .{ }^{* *} P<0.01,{ }^{* * *} P<0.001$ compared with $0 \mathrm{ng} / \mathrm{mL}$ rFGF2.

increased sperm accumulation was observed in the presence of an ascending gradient or homogeneous distribution of rFGF2, suggesting that accumulation was due to a chemokinetic effect of rFGF2. This result agrees with the increment in the velocity determined by computer-assisted sperm analysis. In myoblast cells, it has been observed that FGF2 stimulates migration by chemokinesis, rather than by chemotaxis (Ferreira et al. 2015). In line with our findings, a recent work describes that natriuretic peptide type $C$ induces mouse sperm accumulation, due to an increase in progressive motility and velocity, associated with increments in the intracellular levels of cGMP and $\mathrm{Ca}^{2+}$ (Kong et al. 2017).

Our results also showed that in sperm incubated under capacitating conditions in the presence of rFGF2, there was an increase in intracellular $\mathrm{Ca}^{2+}$ levels. The participation of the FGF2/FGFRs system in the regulation of intracellular $\mathrm{Ca}^{2+}$ concentrations has been previously 
reported in somatic cells (Munaron et al. 1995, Zamburlin et al. 2012, Liu \& Schneider 2014). In our experimental conditions, sperm incubation with rFGF2 also resulted in an increase in acrosomal exocytosis. Considering that $\mathrm{Ca}^{2+}$ ions play a key role in the capacitation process and that an increase in this cation is essential for the occurrence of acrosomal exocytosis (Yanagimachi 1994, Wassarman et al. 2001, Vazquez-Levin \& MarínBriggiler 2009), it can be proposed that rFGF2 induces the acrosomal loss by regulating intracellular $\mathrm{Ca}^{2+}$ concentrations. However, further studies are needed to understand the mechanisms underlying these effects in sperm cells and their physiological relevance. Regarding the rFGF2 concentrations at which the biological effects were found in the present study, our results are in agreement with the biphasic effect of rFGF2 found in somatic cells (Kanodia et al. 2014). It has been proposed that at low/intermediate concentrations of FGF2, there are sufficient free FGFRs available allowing the formation of the FGF2-HSPG-FGFR signaling unit and that at high concentrations of FGF2, FGFR-binding sites become saturated, inhibiting the complex formation.

In summary, our results demonstrate (1) the presence of FGF2 in the mouse uterus, oviduct and COC, (2) the presence of the four FGFRs in sperm cells, mainly localized in the flagellum and acrosomal region and (3) that sperm incubation with rFGF2 led to an increase in sperm motility, in intracellular $\mathrm{Ca}^{2+}$ levels and in acrosomal exocytosis. Results from the present study about the presence and function of FGFRs in mouse sperm are similar to those previously found in human sperm (Saucedo et al. 2015). Altogether, they suggest the relevance of the FGF2/FGFRs system for the regulation of mammalian sperm physiology and led us to propose that in vivo, the FGF2 present in the female reproductive tract would exert a regulatory role on sperm function.

\section{Supplementary data}

This is linked to the online version of the paper at https://doi.org/10.1530/REP-18-0133.

\section{Declaration of interest}

The authors declare that there is no conflict of interest that could be perceived as prejudicing the impartiality of the research reported.

\section{Funding}

This work was supported by grants of the Agencia Nacional de Promoción Científica y Tecnológica (ANPCyT; PICT 2013 \# 627 to C I M B; PICT 2015-2294 to M G B) and the Consejo Nacional de Investigaciones Científicas y Técnicas (CONICET; grant PIP 112-2011-0100740 to M H V L).

\section{Acknowledgements}

The authors thank Dr Alberto Baldi and Dr Adrián Góngora for providing the rFGF2, Florenza La Spina, Gustavo Verón, Dr Guillermina Luque and Dr Pablo Pomata for their technical assistance.

\section{References}

Belov AA \& Mohammadi M 2013 Molecular mechanisms of fibroblast growth factor signaling in physiology and pathology. Cold Spring Harbor Perspectives in Biology 5 a015958. (https://doi.org/10.1101/cshperspect. a015958)

Ben-Haroush A, Abir R, Ao A, Jin S, Kessler-Icekson G, Feldberg D \& Fisch B 2005 Expression of basic fibroblast growth factor and its receptors in human ovarian follicles from adults and fetuses. Fertility and Sterility 84 (Supplement 2) 1257-1268. (https://doi.org/10.1016/j. fertnstert.2005.05.018)

Brukman NG, Miyata H, Torres P, Lombardo D, Caramelo JJ, Ikawa M, Da Ros VG \& Cuasnicú PS 2016 Fertilization defects in sperm from Cysteine-rich secretory protein 2 (Crisp2) knockout mice: implications for fertility disorders. Molecular Human Reproduction 22 240-251. (https://doi.org/10.1093/molehr/gaw005)

Busso D, Goldweic NM, Hayashi M, Kasahara M \& Cuasnicú PS 2007 Evidence for the involvement of testicular protein CRISP2 in mouse sperm-egg fusion. Biology of Reproduction 76 701-708. (https://doi. org/10.1095/biolreprod.106.056770)

Caligioni CS 2009 Assessing reproductive status/stages in mice. Current Protocols in Neuroscience Appendix 4 Appendix 4l. (https://doi. org/10.1002/0471142301.nsa04is48)

Cancilla B \& Risbridger GP 1998 Differential localization of fibroblast growth factor receptor- $1,-2,-3,-4$ in fetal, inmature, and adult rat testes. Biology of Reproduction 58 1138-1145. (https://doi.org/10.1095/ biolreprod58.5.1138)

Cotton L, Gibbs GM, Sanchez-Partida LG, Morrison JR, de Kretser DM \& O'Bryan MK 2006 FGFR-1 (corrected) signaling is involved in spermiogenesis and sperm capacitation. Journal of Cell Science $\mathbf{1 1 9}$ 75-84. (https://doi.org/10.1242/jcs.02704)

Cotton LM, O'Bryan MK \& Hinton BT 2008 Cellular signaling by fibroblast growth factors (FGFs) and their receptors (FGFRs) in male reproduction. Endocrine Reviews 29 193-216. (https://doi.org/10.1210/er.2007-0028)

Deng C, Wynshaw-Boris A, Zhou F, Kuo A \& Leder P 1996 Fibroblast growth factor receptor 3 is a negative regulator of bone growth. Cell $\mathbf{8 4}$ 911-921. (https://doi.org/10.1016/S0092-8674(00)81069-7)

Eisenbach M \& Giojalas LC 2006 Sperm guidance in mammals - an unpaved road to the egg. Nature Reviews Molecular Cell Biology 7 276-285. (https://doi.org/10.1038/nrm1893)

Eswarakumar VP, Lax I \& Schlessinger J 2005 Cellular signaling by fibroblast growth factor receptors. Cytokine and Growth Factor Reviews 16 139-149. (https://doi.org/10.1016/j.cytogfr.2005.01.001)

Ferreira MM, Dewi RE \& Heilshorn SC 2015 Microfluidic analysis of extracellular matrix-bFGF crosstalk on primary human myoblast chemoproliferation, chemokinesis, and chemotaxis. Integrative Biology 7 569-579. (https://doi.org/10.1039/C5IB00060B)

Fon Tacer K, Bookout AL, Ding X, Kurosu H, John GB, Wang L, Goetz R, Mohammadi M, Kuro-o M, Mangelsdorf DJ et al. 2010 Research resource: comprehensive expression atlas of the fibroblast growth factor system in adult mouse. Molecular Endocrinology 24 2050-2064. (https:// doi.org/10.1210/me.2010-0142)

Fraser LR \& Drury LM 1975 The relationship between sperm concentration on fertilization in vitro of mouse eggs. Biology of Reproduction 13 513-518. (https://doi.org/10.1095/biolreprod13.5.513)

Gabler C, Lauer B, Einspanier A, Schams D \& Einspanier R 1997 Detection of mRNA and immunoreactive proteins for acidic and basic fibroblast growth factor and expression of the fibroblast growth factor receptors in the bovine oviduct. Journal of Reproduction and Fertility 109 213-221. (https://doi.org/10.1530/jrf.0.1090213)

Gabler C, Plath-Gabler A, Einspanier A \& Einspanier R 1998 Insulin-like and fibroblast growth factors and their receptors are differentially 
expressed in the oviducts of the common marmoset monkey (Callithrix jacchus) during the ovulatory cycle. Biology of Reproduction $\mathbf{5 8}$ 1451-1457. (https://doi.org/10.1095/biolreprod58.6.1451)

Garbarino Azúa DJ, Saucedo L, Giordana S, Magri ML, Buffone MG, Neuspiller F, Vazquez-Levin MH \& Marín-Briggiler CI 2017 Fibroblast growth factor 2 (FGF2) is present in human spermatozoa and is related with sperm motility. The use of recombinant FGF2 to improve motile sperm recovery. Andrology 5 990-998. (https://doi.org/10.1111/ andr.12398)

Gatica LV, Guidobaldi HA, Montesinos MM, Teves ME, Moreno Al, Uñates DR, Molina RI \& Giojalas LC 2013 Picomolar gradients of progesterone select functional human sperm even in subfertile samples. Molecular Human Reproduction 19 559-69. (https://doi.org/10.1093/ molehr/gat037)

Givol D \& Yayon A 1992 Complexity of FGF receptors: genetic basis for structural diversity and functional specificity. FASEB Journal $\mathbf{6}$ 3362-3369. (https://doi.org/10.1096/fasebj.6.15.1464370)

Gong SG 2014 Isoforms of receptors of fibroblast growth factors. Journal of Cellular Physiology 229 1887-1895. (https://doi.org/10.1002/jcp.24649)

Guagnano V, Furet P, Spanka C, Bordas V, Le Douget M, Stamm C, Brueggen J, Jensen MR, Schnell C, Schmid H et al. 2011 Discovery of 3-(2,6-dichloro-3,5-dimethoxy-phenyl)-1-\{6-[4-(4-ethyl-piperazin-1-yl)phenylamino]-pyrimidin-4-yl\}-1-methyl-urea (NVPBGJ398), a potent and selective inhibitor of the fibroblast growth factor receptor family of receptor tyrosine kinase. Journal of Medicinal Chemistry 54 7066-7083. (https://doi.org/10.1021/jm2006222)

Giojalas LC, Guidobaldi HA \& Sánchez R 2015 Sperm chemotaxis in mammals. In: Flagellar Mechanics and Sperm Guidance, pp 272-307. Ed J CossonSharjah, United Arab Emirates:Bentham Science Publishers.

Guidobaldi HA, Hirohashi N, Cubilla M, Buffone MG \& Giojalas LC 2017 An intact acrosome is required for the chemotactic response to progesterone in mouse spermatozoa. Molecular Reproduction and Development 84 310-315. (https://doi.org/10.1002/mrd.22782)

Hasegawa K \& Saga Y 2014 FGF8-FGFR1 signaling acts as a niche factor for maintaining undifferentiated spermatogonia in the mouse. Biology of Reproduction 91 145. (https://doi.org/10.1095/ biolreprod.114.121012)

Hughes SE 1997 Differential expression of the fibroblast growth factor receptor (FGFR) multigene family in normal human adult tissues. Journal of Histochemistry and Cytochemistry 45 1005-1019. (https://doi. org/10.1177/002215549704500710)

Johnson DE \& Williams LT 1993 Structural and functional diversity in the FGF receptor multigene family. Advances in Cancer Research 60 1-41.

Kamura S, Matsumoto Y, Fukushi JI, Fujiwara T, lida K, Okada Y \& I wamoto Y 2010 Basic fibroblast growth factor in the bone microenvironment enhances cell motility and invasion of Ewing's sarcoma family of tumours by activating the FGFR1-PI3K-Rac1 pathway. British Journal of Cancer 103 370-381. (https://doi.org/10.1038/sj.bjc.6605775)

Kanodia J, Chai D, Vollmer J, Kim J, Raue A, Finn G \& Schoeberl B 2014 Deciphering the mechanism behind Fibroblast Growth Factor (FGF) induced biphasic signal-response profiles. Cell Communication and Signaling 15 12-34. (https://doi.org/10.1186/1478-811X-12-34)

Kong N, Xu X, Zhang Y, Wang Y, Hao X, Zhao Y, Qiao J, Xia G \& Zhang M 2017 Natriuretic peptide type $C$ induces sperm attraction for fertilization in mouse. Scientific Reports 7 39711. (https://doi.org/10.1038/ srep39711)

Kubota Y \& Ito K 2000 Chemotactic migration of mesencephalic neural crest cells in the mouse. Developmental Dynamics 217 170-179. (https://doi.org/10.1002/(SICI)1097-0177(200002)217:2<170::AIDDVDY4>3.0.CO;2-9)

Lai MS, Wang CY, Yang SH, Wu CC, Sun HS, Tsai SJ, Chuang JI, Chen YC \& Huang BM 2016 The expression profiles of fibroblast growth factor 9 and its receptors in developing mice testes. Organogenesis 12 61-77. (https://doi.org/10.1080/15476278.2016.1171448)

Li S, Lan Z, Li X, Lin J \& Lei Z 2014 Role of postnatal expression of FGFR1 and FGFR2 in testicular germ cells on spermatogenesis and fertility in mice. Journal of Reproduction and Infertility 15 122-133.

Liu Y \& Schneider MF 2014 FGF2 activates TRPC and $\mathrm{Ca}(2+)$ signaling leading to satellite cell activation. Frontiers in Physiology 5 38. (https:// doi.org/10.3389/fphys.2014.00038)

Malamitsi-Puchner A, Sarandakou A, Baka SG, Tziotis J, Rizos D, Hassiakos D \& Creatsas G 2001 Concentrations of angiogenic factors in follicular fluid and oocyte-cumulus complex culture medium from women undergoing in vitro fertilization: association with oocyte maturity and fertilization. Fertility and Sterility 76 98-101.

Marín-Briggiler Cl, Vazquez-Levin $\mathrm{MH}$, Gonzalez-Echeverría F, Blaquier JA, Tezón JG \& Miranda PV 1999 Strontium supports human sperm capacitation but not follicular fluid-induced acrosome reaction. Biology of Reproduction 61 673-680.

Marín-Briggiler CI, Veiga MF, Matos ML, Echeverría MF, Furlong LI \& Vazquez-Levin MH 2008 Expression of epithelial cadherin in the human male reproductive tract and gametes and evidence of its participation in fertilization. Molecular Human Reproduction 14 561-571. (https://doi. org/10.1093/molehr/gan053)

Mohammadi M, Olsen SK \& Ibrahimi OA 2005 Structural basis for fibroblast growth factor receptor activation. Cytokine and Growth Factor Reviews 16 107-137. (https://doi.org/10.1016/j.cytogfr.2005.01.008)

Munaron L, Distasi C, Carabelli V, Baccino FM, Bonelli G \& Lovisolo D 1995 Sustained calcium influx activated by basic fibroblast growth factor in Balb-c 3T3 fibroblasts. Journal of Physiology 484 557-566. (https:// doi.org/10.1113/jphysiol.1995.sp020686)

Ornitz DM \& Itoh N 2001 Fibroblast growth factors. Genome Biology 2 REVIEWS3005.

Ornitz DM \& Itoh N 2015 The fibroblast growth factors signaling pathway. WIRES Developmental Biology 4 215-266. (https://doi.org/10.1002/ wdev.176)

Russell L, Ettlin R, Sinha A \& Clegg E 1990 Histological and Histopathological of the Testis. Florida: Cache River Press.

Saucedo L, Buffa GN, Rosso M, Guillardoy T, Góngora A, Munuce MJ, Vazquez-Levin MH \& Marín-Briggiler C 2015 Fibroblast growth factor receptors (FGFRs) in human sperm: expression, functionality and involvement in motility regulation. PLOS ONE 10 e0127297. (https://doi. org/10.1371/journal.pone.0127297)

Steger K, Tetens F, Seitz J, Grothe C \& Bergmann M 1998 Localization of fibroblast growth factor 2 (FGF-2) protein and the receptors FGFR $1-4$ in normal human seminiferous epithelium. Histochemistry and Cell Biology 110 57-62. (https://doi.org/10.1007/s004180050265)

Turner N \& Grose R 2010 Fibroblast growth factor signalling: from development to cancer. Nature Reviews Cancer 10 116-129. (https:// doi.org/10.1038/nrc2780)

Vazquez-Levin MH \& Marín-Briggiler CI 2009 An overview of the molecular mechanisms envolved in human fertilization. In Infertility in the Male. Eds LT Lipshultz, SS Howards \& CS Niederberger. Cambridge University Press.

Wassarman PM, Jovine L \& Litscher ES 2001 A profile of fertilization in mammals. Nature Cell Biology 3 E59-E64. (https://doi. org/10.1038/35055178)

Weinstein M, Xu X, Ohyama K \& Deng CX 1998 FGFR-3 and FGFR-4 function cooperatively to direct alveogenesis in the murine lung. Development 125 3615-3623.

Yanagimachi R 1994 Mammalian fertilization. In The Physiology of Reproduction, pp 189-317. Eds E Knobil \& JD Neill. New York: Raven Press.

Yu C, Wang F, Kan M, Jin C, Jones RB, Weinstein M, Deng CX \& McKeehan WL 2000 Elevated cholesterol metabolism and bile acid synthesis in mice lacking membrane tyrosine kinase receptor FGFR4. Journal of Biological Chemistry 275 15482-15489. (https://doi. org/10.1074/jbc.275.20.15482)

Yu PJ, Ferrari G, Galloway AC, Mignatti P \& Pintucci G 2007 Basic fibroblast growth factor (FGF-2): the high molecular weight forms come of age. Journal of Cellular Biochemistry 100 1100-1108. (https://doi. org/10.1002/jcb.21116)

Zamburlin P, Ruffinatti FA, Gilardino A, Farcito S \& Lovisolo D 2012 Calcium signals induced by FGF-2 in parasympathetic neurons: role of second messenger pathways. Neuroscience Letters 523 30-34. (https:// doi.org/10.1016/j.neulet.2012.06.035)

Received 9 March 2018

First decision 25 March 2018

Revised manuscript received 22 May 2018

Accepted 1 June 2018 